\title{
Antinociceptive Activity of Nortriptyline through the Adrenergic System - an in vivo Study in Mice
}

\author{
Fatemeh Tavakoli ${ }^{1}$, Seyed Hassan Hejazian ${ }^{2}$, Seyyed Mohsen Anoosheh ${ }^{1, *}$
}

\section{Fatemeh Tavakoli ${ }^{1}$, Seyed Hassan Hejazian², Seyyed Mohsen Anoosheh ${ }^{1, *}$}

\section{'Department of Pharmacology,} Shahid Sadoughi University of Medical Sciences, Yazd, IRAN.

${ }^{2}$ Department of Physiology, Shahid Sadoughi University of Medical Sciences, Yazd, IRAN.

\section{Correspondence}

\section{Dr. Seyyed Mohsen Anoosheh}

Department of Pharmacology, Shahid Sadoughi University of Medical Sciences, Yazd, IRAN

Phone: +983518203410-17

Email: mohsenanoosheh44@gmail. com

\section{History}

- Submission Date: 25-08-2018

- Review completed: 18-09-2018;

- Accepted Date: 31-10-2018.

DOI : 10.5530/ijcep.2018.5.3.3

\section{Copyright}

(C) 2018 Phcog.Net. This is an openaccess article distributed under the terms of the Creative Commons Attribution 4.0 International license.

\begin{abstract}
Background and Aim: Neuropathic pain results from nerve injury and nortriptyline, an antidepressant drug, has been approved for the treatment of several types of neuropathic pain. In this study we investigated the antinociceptive effect nortriptyline (45mg/kg body weight) of nortriptyline on thermal and acetic acid induced pain in mice. Methods: nortriptyline was dissolved in distillated water and injected i.p to male mice 15 minute before the onset of experiment. Writhing and hot-plate tests were applied to study the analgesic effect of nortriptyline and compared with that of diclofenac sodium $(30 \mathrm{mg} / \mathrm{kg}$, i.p.) or morphine $(8 \mathrm{mg} / \mathrm{kg}$, i.p). To investigate the mechanisms involved in antinociception, glutamic acid, naloxone, yohimbine, atropine, propranolol and ondansetron were used. These drugs were injected intraperitoneally 15 min before the administration of nortriptyline. The number of writhes were counted in 30 minutes and analyzed. Results: In this study nortriptyline exhibited a significant antinociceptive effect in both chronic and acute pain in mice. The antinociceptive effect induced by this gum in the writhing and hot plate test was reversed by the systemic administration of propranolol ( $\beta$-adrenergic antagonist) and ondansetron but glutamic acid, naloxone and atropine did not reverse this effect. Conclusion: The findings of this study indicated that nortriptyline induced its antinociceptive through the adrenergic and/ or serotonergic system.
\end{abstract}

Key words: Nortriptyline, Hot-plate, Writhing test.

\section{INTRODUCTION}

In humans, pain has injurious effects on sleep, cognitive abilities such as learning, attention and the capacity for work. ${ }^{[1]}$ Pain is caused following tissue or peripheral nerve damage or injuries to different parts of the central nervous system in humans and animals. Antidepressants have antinociceptive effects in addition to antidepressant activity. ${ }^{[2]}$ Although thorough comparisons of the antinociceptive potencies of clinically used antidepressants have not been conducted, previous study suggested that classic tricyclic antidepressants exert more potent antinociceptive effects than selective serotonin reuptake inhibitors. ${ }^{[3]}$ The neurochemical mechanisms of antinociceptive effects of antidepressants have not been well described. Most antidepressants inhibit the reuptake of monoamines, including norepinephrine and serotonin at neuronal terminals. ${ }^{[4]}$ Increased levels of monoamines in synaptic clefts are therefore presumed to lead to changes in pain thresholds and induce antinociception. However, there is still controversy over the identity of the monoamine receptors responsible for these analgesic effects, in addition to their location. ${ }^{[5]}$ However studies on antinociceptive effect of these agents in acute pain management are lacking to support their use in such a pain state, though the nortriptyline has shown to have some analgesic effect in patients with acute pain. ${ }^{[6]}$ In 2010, an evidencebased guideline sponsored by the International Association for the Study of Pain recommended nortriptyline as a first-line medication for neuropathic pain. ${ }^{[7]}$ Thus, in this study, we attempted to determine the identity and possible mechanism of antidepressants, by investigating antagonism of antidepressant-induced antinociception after peripheral or central administration pain.

\section{MATERIALS AND METHODS}

\section{Animals}

90 male albino mice (25-30 g) with 6-8 weeks old that bred in animal house of Shahid Sadoughi Medical School were selected. Animals were housed at controlled temperature $\left(22 \pm 2^{\circ} \mathrm{C}\right)$ with a $12 \mathrm{~h}$-light/dark cycle and with standard lab chow and tap water ad libitum. Each animal was used only once. The experiments reported in this study were carried out in accordance with current ethical guidelines for the investigation of experimental pain in conscious animals. The numbers of animals and intensities of noxious stimuli used were the minimum necessary to demonstrate the consistent effects of the drug treatments. ${ }^{[8]}$

Cite this article: Tavakoli F, Hejazian SH, Anoosheh SM. Antinociceptive Activity of Nortriptyline through the Adrenergic System - an in vivo Study in Mice. Int J Clin Exp Physiol. 2018;5(3):120-2. 


\section{Drugs administration}

Morphine hydrochloride $(8 \mathrm{mg} / \mathrm{kg})$ and Diclofenac sodium $(30 \mathrm{mg} / \mathrm{kg})$ were intraperitoneally (i.p.) administered as positive control groups. Naloxone $(5 \mathrm{mg} / \mathrm{kg})$, glutamic acid, (5mg/kg, i.p.), atropine, $(5 \mathrm{mg} / \mathrm{kg}$, i.p.), propranolol (8 mg/kg, p.o) and ondansetron $(5 \mathrm{mg} / \mathrm{kg}$, i.p.) was also used for investigation of action mechanism intraperitoneally. ${ }^{[9]}$

\section{Hot-plate test}

The hot-plate test was carried out according to the method previously described ${ }^{[10]}$ Briefly, before the initial of experiment, mice were habituated to a Plexiglas cylinder for $5 \mathrm{~min}$. In these experiments, the hot-plate apparatus was maintained at $54 \pm 0.1^{\circ} \mathrm{C}$. Animals were placed into an acrylic cylinder $(20 \mathrm{~cm}$ in diameter) on the heated surface and the time (in seconds) between placement and licking of their hind paws or jumping (whichever occurred first), was recorded as the response latency (reaction time). Each mouse served as its own control. A 45-s cut-off was used to prevent tissue damage. After baseline behavior tests, mice were immediately administered with drugs. The reaction time of each mouse was again valuated at 15, 30, 45 and 60 , min after treatment. This final test mean value represented the after treatment reaction time and was subsequently used to determine the percentage thermal pain stimulus or protection by applying the following formula:

$$
\% \mathrm{MPE}=\frac{\text { Test latency }- \text { Control latency }}{\text { Cut off }- \text { Control latency }} \times 100
$$

\section{Acetic acid-induced writhing test}

The abdominal constriction test was used to measure the analgesic activity of nortriptyline. Male mice pre-treated with drugs and 15 min later, all mice were treated with intraperitoneal injection of $0.6 \%$ acetic acid to cause a typical stretching response. Five min after acetic acid injection, mice were kept in individual cages and writhing or stretching of each mouse was counted for a period of $30 \mathrm{~min}$ by a blinded individual. The analgesic effect was measured by calculating the mean reduction in the number of abdominal constrictions for each drug as compared to saline control. Percentage inhibition of writhing was calculated by using the following formula: ${ }^{[11]}$

$$
\% \text { Inhibition }=\frac{\begin{array}{l}
\text { Mean number of writhes (control) }- \\
\text { Mean number of writhes }(\text { test })
\end{array}}{\text { writhes (control) }}
$$

\section{Assessment of some mechanisms involved in antinociceptive activity}

To investigate the possible mechanisms by which nortriptyline inhibits acetic acid induced nociception, mice were pre-treated with different drugs include naloxone ( $5 \mathrm{mg} / \mathrm{kg}$, i.p.), glutamic acid, (5mg/kg, i.p.), atropine, (5mg/kg, i.p.), propranolol (8 $\mathrm{mg} / \mathrm{kg}$, p.o) and ondansetron $(5 \mathrm{mg} / \mathrm{kg}$, i.p.). After $15 \mathrm{~min}$, the animals received an injection of nortriptyline $(45 \mathrm{mg} / \mathrm{kg}$, i.p.) and $15 \mathrm{~min}$ later acetic acid was injected. The number of writhes was counted to analyze. The doses of antagonists were selected on the basis of earlier literature data and in pilot experiment in our laboratory. The writhing test was chosen for this purpose because of the specificity and sensitivity in nociception transmission that this model provides. ${ }^{[12]}$

\section{Data analysis}

All data are expressed as the mean \pm standard error of the means (S.E.M.). Graph pad prism 5 was used to analyze behavior studies. Statistically significant differences were determined using one-way ANOVA with the Tukey Kramer post-test for multiple comparisons. The values of $P<0.05$ were regarded as statistically significant.

\section{RESULTS}

\section{Hot-plate test}

In this study we investigated the effect of nortriptyline on acute and chronic pain. Latency responses for animals in different groups are shown in Table 1 . The latencies for time 0 (base line latency) were statically analyzed by one way ANOVA and there was no significant difference between the groups. Our data analysis showed that nortriptyline has a maximum analgesic effect against thermally induced pain at 15 $\min (P<0.01)$. Our results showed that pre-treatment of animals with the beta aderno receptor antagonist, propranolol and serotonergic antagonist significantly prevented the anti-nociception action produced by nortriptyline $45 \mathrm{mg} / \mathrm{kg}$. Other antagonist, naloxone, atropine, glutamic acid, yohimbine could not reverse anti-nociception effect of nortriptyline.

\section{Acetic acid-induced writhing test}

The effect of nortriptyline on acetic acid induced writhing is presented in Table 2 . Nortriptyline reduced acetic acid-induced writhing significantly. We also investigated some mechanisms related to chronic induced antinociception. Our results showed that pre-treatment of animals with the beta aderno receptor antagonist, propranolol and serotonergic antagonist significantly prevented the anti-nociception action produced by

\begin{tabular}{|c|c|c|c|c|c|}
\hline \multicolumn{6}{|c|}{ Latency time (s) } \\
\hline Group & 0 & 15 & 30 & 45 & 60 \\
\hline Control & $9.7 \pm 2.1$ & $11.3 \pm 3.2$ & $9.6 \pm 1.6$ & $9.2 \pm 2.8$ & $9.1 \pm 2.5$ \\
\hline nortriptyline 45 (mg/kg) & $9.2 \pm 1.6$ & $14.4 \pm 3.9^{*}$ & $11.4 \pm 2.6$ & $10.3 \pm 2.4$ & $10.3 \pm 2.3$ \\
\hline Nortriptyline+ atropine & $7.6 \pm 0.9$ & $13.1 \pm 3.2^{*}$ & $11.9 \pm 2.5^{*}$ & $10.9 \pm 2.8^{*}$ & $9.1 \pm 3.1^{*}$ \\
\hline Nortriptyline+ propranolol & $8.6 \pm 1.5$ & $10.3 \pm 3.4$ & $10.6 \pm 2.9^{*}$ & $9.2 \pm 1.7$ & $9.9 \pm 2.1$ \\
\hline Nortriptyline+ glutamic acid & $9.2 \pm 1.6$ & $14.4 \pm 3.9^{*}$ & $11.4 \pm 2.6$ & $10.3 \pm 2.4$ & $10.3 \pm 2.3$ \\
\hline Nortriptyline+ ondansetron & $7.6 \pm 0.9$ & $8.1 \pm 3.2$ & $8.5 .9 \pm 2.5^{*}$ & $7.9 \pm 2.8^{*}$ & $9.1 \pm 3.1^{*}$ \\
\hline Nortriptyline+ naloxone & $8.6 \pm 1.5$ & $14.3 \pm 3.4^{*}$ & $10.8 \pm 2.9^{*}$ & $9.4 \pm 1.7$ & $9.3 \pm 2.1$ \\
\hline Nortriptyline+ yohimbine & $9.2 \pm 1.6$ & $14.4 \pm 3.9^{*}$ & $11.4 \pm 2.6$ & $10.3 \pm 2.4$ & $10.3 \pm 2.3$ \\
\hline Morphine8(mg/kg) & $8.5 \pm 1.6$ & $15.9 \pm 3.4^{*}$ & $16.9 \pm 4.2^{*}$ & $13.4 \pm 3.7^{\star}$ & $11.8 \pm 4.8^{*}$ \\
\hline
\end{tabular}
nortriptyline $45 \mathrm{mg} / \mathrm{kg}$. Other antagonist, naloxone, atropine, glutamic

Table 1: Hot plate latency responses of animals in different groups $(n=6)$.

The analysis of latency times of different groups. The baseline time of each group is considered as control and other times compare with baseline. ${ }^{*} P<0.05$ 
Table 2: The effect of SEOFAF on acetic acid-induced writhing in mice $(n=6)$.

$\begin{array}{|ccc|}\text { Group } & \text { Number of writhing } & (\%) \text { Inhibition } \\ \text { Control } & 106.4 \pm 2.1 & - \\ \text { Nortriptyline 45 }(\mathrm{mg} / \mathrm{kg}) & 59.9 \pm 1.6^{*} & 43.7 \\ \text { Nortriptyline+ atropine } & 66.8 \pm 1.5^{*} & 66.1 \\ \text { Nortriptyline+ propranolol } & 98.9 \pm 4.1^{* *} & 11.2 \\ \text { Nortriptyline+ glutamic acid } & 718 \pm 1.5^{*} & 35.0 \\ \text { Nortriptyline+ ondansetron } & 101 \pm 4.6 & 7.5 \\ \text { Nortriptyline+ naloxone } & 67.9 \pm 6.2 & 38.1 \\ \text { Nortriptyline+ yohimbine } & 73.8 \pm 3.9 & 48.0 \\ \text { Sodium Diclofenac(mg/kg) } & 35.9 \pm 2.9^{*} & 95.5\end{array}$

${ }^{*} p<0.05$ compare to the control group and ${ }^{* *} p<0.05$ compare to sodium diclofenac group. Values are the mean \pm SEM for at least 8 mice per group. SEOFAF: seed essential oil of Ferula assa-foetida.

acid, yohimbine could not reverse anti-nociception effect of nortriptyline.

\section{DISCUSSION}

We tested the effect of the nonselective antagonist propranolol and found that it blocked the antial-lodynic action of nortriptyline without affecting the nociceptive threshold of control or neuropathic mice per se. This critical role played by is not due to because specific antagonists of these receptors did not alter the action of nortriptyline. The pharmacological data, together with the loss of nortriptyline action in mice deficient for, demonstrate that are critical for the antiallodynic property of this TCA.

The most common hypothesis for the analgesic action of TCAs concerns the recruitment of noradrenergic descending pathways that inhibit nociceptive responses. It was considered that this action was mainly exerted through the. However, they are also known to be expressed within the dorsal horn of the spinal cord, which is a critical relay for nociceptive information. This location within the nociceptive system could potentially constitute a neuroanatomical substrate for nortriptyline and descending noradrenergic inhibitory pathways to influence neuropathic allodynia. Antidepressant action against depression necessitates a chronic treatment, which led to the idea that these drugs act via long-term molecular and neural plasticity. TCA action against neuropathic pain is faster, but it still necessitates a prolonged treatment. ${ }^{[13,14]}$

Our results show that the delay for therapeutic onset (10-12 days) and offset (2-3 days) are different. Moreover, when we administered nortriptyline again after interruption of TCA treatment and allodynia relapse, the therapeutic onset required only 3 days (data not shown).

This suggests that two levels of plasticity might be implicated in the antiallodynic action of nortriptyline. We previously demonstrated that deltaopioid receptors (DORs) are acting as final mediators.

\section{ACKNOWLEDGEMENT}

Non.

\section{CONFLICT OF INTEREST}

The authors declare no conflict of interest.

\section{ABBREVIATIONS USED}

SEOFAF: Seed essential oil of Ferula assa-foetida.

\section{SUMMARY}

In the present study, we investigated the antinociceptive effect $(45 \mathrm{mg} / \mathrm{kg}$ body weight) of nortriptyline on thermal and acetic acid induced pain in mice. Nortriptyline was dissolved in distillated water and injected i.p to male mice 15 minute before the onset of experiment. Writhing and hotplate tests were applied to study the analgesic effect of nortriptyline and compared with that of diclofenac sodium $(30 \mathrm{mg} / \mathrm{kg}$, i.p.) or morphine ( $8 \mathrm{mg} / \mathrm{kg}$, i.p). To investigate the mechanisms involved in antinociception, glutamic acid, naloxone, yohimbine, atropine, propranolol and ondansetron were used. These drugs were injected intraperitoneally 15 min before the administration of nortriptyline. The number of writhes were counted in 30 minutes and analyzed. Nortriptyline exhibited a significant antinociceptive effect in both chronic and acute pain in mice. The antinociceptive effect induced by this gum in the writhing and hot plate test was reversed by the systemic administration of propranolol ( $\beta$-adrenergic antagonist) and ondansetron but glutamic acid, naloxone and atropine did not reverse this effect. The findings of this study indicated that nortriptyline induced its antinociceptive through the adrenergic and/ or serotonergic system.

\section{REFERENCES}

1. Budge C, Carryer J, Boddy J. Learning from people with chronic pain: messages for primary care practitioners. Journal of Primary Health care. 2012;4(4):306-12

2. Kluetsch RC, Schmahl C, Niedtfeld I, Densmore M, Calhoun VD, Daniels J, et al. Alterations in default mode network connectivity during pain processing in borderline personality disorder. Archives of General Psychiatry. 2012;69(10): 993-1002

3. Lee KC, Chiu TT, Lam TH. The role of fear-avoidance beliefs in patients with neck pain: relationships with current and future disability and work capacity. Clinical Rehabilitation. 2007;21(9):812-21.

4. Donck AV, Vranken JH, Puylaert M, Hayek S, Mekhail N, Zundert JV. Intrathecal Drug Administration in Chronic Pain Syndromes. Pain Practice: The Official Journal of World Institute of Pain. 2013.

5. Gray AM, Pache DM, Sewell RD. Do alpha2-adrenoceptors play an integral role in the antinociceptive mechanism of action of antidepressant compounds?. Eur J Pharmacol 1999;378(2):161-8.

6. Onghena P, Houdenhove BV. Antidepressant-induced analgesia in chronic non-malignant pain: a meta-analysis of 39 placebo-controlled studies. Pain. 1992;49(2):205-19.

7. Sindrup SH, Jensen TS. Efficacy of pharmacological treatments of neuropathic pain: an update and effect related to mechanism of drug action. Pain 1999;83(3):389-400

8. Otsuka N, Kiuchi Y, Yokogawa F, et al. Antinociceptive efficacy of antidepressants: assessment of five antidepressants and four monoamine receptors in rats. J Anesth. 2001;15(3):154-8.

9. Richelson E, Pfenning M. Blockade by antidepressants and related compounds of biogenic amine uptake into rat brain synaptosomes: most antidepressants selectively block norepinephrine uptake. Eur J Pharmacol. 1984;104(3-4):277-86

10. Korzeniewska-Rybicka I, Plaznik A. Analgesic effect of antidepressant drugs. Pharmacol Biochem Behav. 1998;59(2):331-8.

11. Tura $B$, Tura SM. The analgesic effect of tricyclic antidepressants. Brain Res. 1990;518(1-2):19-22

12. Zimmermann M. Ethical guidelines for investigations of experimental pain in conscious animals. Pain. 1983;16(2):109-10.

13. Ferreira J, Campos MM, Araújo R, Bader M, Pesquero JB, Calixto JB. The use of kinin $B<$ sub $>1</$ sub $>$ and $B<$ sub $>2</$ sub $>$ receptor knockout mice and selective antagonists to characterize the nociceptive responses caused by kinins at the spinal level. Neuropharmacology. 2002;43(7):1188-97.

14. Collier H, Dinneen L, Johnson CA, Schneider C. The abdominal constriction response and its suppression by analgesic drugs in the mouse. British Journal of Pharmacology and Chemotherapy. 1968;32(2):295-310.

Cite this article: Tavakoli F, Hejazian SH, Anoosheh SM. Antinociceptive Activity of Nortriptyline through the Adrenergic System - an in vivo Study in Mice. Int J Clin Exp Physiol. 2018;5(3):120-2. 